\title{
SISTEM PENDUKUNG KEPUTUSAN PENERIMA BEASISWA BIDIKMISI MENGGUNAKAN METODE SMART
}

\author{
Sukamto $^{1 *}$, Yanti Andriyani ${ }^{1}$, Ayu Lestari ${ }^{1}$ \\ ${ }^{1}$ Sistem Informasi, FMIPA Universitas Riau \\ email: "sukamto@lecturer.unri.ac.id
}

\begin{abstract}
Scholarships are provided selectively according to the type of learning held. There are so many scholarships offered to students who are outstanding and poor, one of which is the scholarship provided by the University of Riau, named Bidikmisi scholarship. The evaluation process of prospective scholarship recipients is carried out by the committee directly and is still done manually. So that it allows the creation of a support system for the decision to accept Bidikmisi scholarships using the smart web-based method. The system created, designed using UML diagrams, the system has made using the PHP programming language and database. The resulting system can process using ten experimental data obtained a sequence of values from highest to smallest, with the highest amount of 0.75 .
\end{abstract}

Keywords: Bidikmisi; Decision Support System; Scholarship; Smart Method.

\begin{abstract}
Abstrak: Pemberian beasiswa dilakukan secara selekif sesuai dengan jenis beasiswa yang diadakan. Banyak sekali beasiswa yang ditawarkan kepada mahasiswa yang berprestasi dan kurang mampu, salah satunya beasiswa yang ditawarkan universitas riau yaitu beasiswa bidikmisi. Proses Penilaian calon penerima beasiswa dilakukan oleh panitia secara langsung dan masih dilakukan secara manual. Sehingga memungkinkan dibuatnya suatu sistem pendukung keputusan penerimaan beasiswa bidikmisi menggunakan metode smart berbasis web. Sistem yang dibuat, dirancang menggunakan UML diagram, pembuatan sistem menggunakan bahasa pemrograman PHP dan database. Sistem yang dihasilkan mampu mengolah data mahasiswa, mengolah data calon penerima untuk dihitung dan laporan jumlah calon penerima yang diterima dan ditolak. Hasil akhir dengan menggunakan 10 data percobaan diperoleh urutan nilai dari yang tertinggi sampai terkecil, dengan nilai tertinggi 0,75 .
\end{abstract}

Kata kunci: Beasiwa; Bidikmisi; Sistem Pendukung Keputusan; Smart.

\section{PENDAHULUAN}

Program beasiswa bidikmisi merupakan bantuan biaya pendidikan yang hanya ditujukan untuk calon mahasiswa tidak mampu (miskin), berfokus kepada yang memiliki keterbatasan kemampuan ekonomi. Meskipun demikian, syarat prestasi pada bidikmisi ditujukan untuk menjamin bahwa penerima bidikmisi terseleksi, dan benarbenar mempunyai potensi dan kemampuan untuk menyelesaikan pendidikan tinggi.

Beasiswa bidikmisi ada pada setiap tahun dan diperuntukkan bagi mahasiswa baru, sesuai dengan peraturan yang telah ditentukan oleh bidikmisi 
Universitas Riau, antara lain kriteriakriteria untuk menentukan siapa yang terpilih dan layak untuk menerima beasiswa sesuai dengan syarat-syarat yang telah ditentukan. Oleh sebab itu tidak semua peserta yang mendaftarkan diri sebagai calon penerima beasiswa bidikmisi diterima, hanya yang memenuhi kriteria saja yang akan memperolehnya. Jumlah peserta yang mengajukan cukup banyak, dan indikator untuk seleksi berkas pengajuan masih menggunakan cara manual. Sehingga pengolahan data kurang efektif, dan juga membutuhkan waktu yang relatif lama. Untuk itu diperlukan sistem pendukung keputusan.

Adapun tujuan penelitian ini adalah membangun sistem pendukung keputusan (SPK) yang dapat menentukan penerima beasiswa bidikmisi khususnya di FMIPA Universitas Riau menggunakan metode SMART.

Sistem pendukung keputusan adalah sistem informasi yang menyediakan informasi, pemodelan, dan manipulasi data [1]. Beberapa penelitian SPK antara lain, penentuan mitra jasa pengiriman barang terbaik metode TOPSIS [2], menggunakan metode AHP [3], pemilihan matakuliah pilihan dengan metode AHP [4], pemilihan pelanggan terbaik dengan metode SAW [5], pemilihan guru dan pegawai terbaik dengan metode MOORA [6], pemberian kredit rumah sejahtera dengan metode TOPSIS [7], penerimaan calon guru honor dengan metode TOPSIS [8], dan penentuan mahasiswa berprestasi dengan metode WP [9].

Selanjutnya penelitian tentang metode SMART dapat digunakan antara lain, untuk pemilihan sekolah Paud [10], pemilihan kegiatan ekstra-kurikuler [11], penentuan prioritas rehabilitasi dan rekonstruksi pasca-bencana alam [12], penentuan penem-patan karyawa baru di PDAM Kisaran [13], dan penentuan kualitas pema-sukan pangan segar [14]. Penelitian tentang beasiswa bidik misi sudah dilakukan menggu-nakan metode SAW [15].

\section{METODE}

Proses pengumpulan data di bagian Kemahasiswaan dan Panitia penerimaan beasiswa bidikmisi FMIPA Universitas Riau tahun 2018.

Metode SMART merupakan suatu model pengambilan keputusan dengan memperhatikan hal-hal bersifat kualitatif dan kuantitatif. Parameter menjadi penentu keputusan dan memiliki range nilai dan bobot yang berbedabeda. Adapun langkah-langkahnya sebagai berikut [16] :

1) Menghitung normalisasi kriteria dengan membandingkan nilai bobot kriteria dengan jumlah bobot kriteria, dengan persamaan :

$$
W_{j}=\frac{w_{j}}{\sum_{j=1}^{m} w_{j}}
$$

dimana :

$W_{j}=$ normalisasi bobot kriteria ke $j$

$w_{j}=$ nilai bobot kriteria ke $j$

$j=$ jumlah kriteria

2) Menentukan nilai utility setiap kriteria. Nilai utiliti ini tergantung pada sifat kriteria itu sendiri, yaitu :

a) Kriteria yang bersifat "lebih diinginkan nilai yang lebih kecil", dengan persamaan :

$$
u_{i}\left(a_{i}\right)=\left(\frac{C_{\max }-C_{o u t}}{C_{\max }-C_{\min }}\right)
$$

b) Kriteria yang bersifat "lebih diinginkan nilai yang lebih besar", dengan persamaan :

$u_{i}\left(a_{i}\right)=\left(\frac{C_{\text {out }}-C_{\min }}{C_{\max }-C_{\min }}\right)$

dimana : 
DOI: https://doi.org/10.33330/jurteksi.v6i3.549

Available online at http://jurnal.stmikroyal.ac.id/index.php/jurteksi

$$
\begin{aligned}
u_{i}\left(a_{i}\right)= & \text { nilai utility kriteria ke } i \\
& \text { untuk ke } i \\
C_{\max }= & \text { nilai kriteria maksimal } \\
C_{\min }= & \text { nilai kriteria minimum } \\
C_{\text {out }}= & \text { nilai kriteria ke } i
\end{aligned}
$$

3) Menghitung nilai akhir, dengan persamaan:

$$
u\left(a_{i}\right) \sum_{j=1}^{m} w_{j} u_{i}\left(a_{i}\right)
$$

dimana :

$u\left(a_{i}\right)=$ nilai total alternatif

$w_{j} \quad=$ hasil normalisasi bobot kriteria

$u_{i}\left(a_{i}\right)=$ hasil penentuan nilai utility

\section{HASIL DAN PEMBAHASAN}

Jumlah data sebanyak 10 orang, sebagaimana tabel 1 .

Tabel 1. Data Mahasiswa

\begin{tabular}{ccl}
\hline No & NIM & Nama Mahasiswa \\
\hline 1 & 1603115225 & Anisa Rahmalia \\
\hline 2 & 1503114632 & Sesri Jumiatul Erda \\
\hline 3 & 1503113000 & Fisky Amelia T. \\
\hline 4 & 1503117345 & Destry Natasya G. \\
\hline 5 & 1503114835 & Aria Shabry \\
\hline 6 & 1403110831 & Muh. Hidayat \\
\hline 7 & 1403113611 & Muhammad Yasir \\
\hline 8 & 1503121139 & Selly Mitra M. \\
\hline 9 & 1503117235 & Martiti Silfia \\
\hline 10 & 1503113119 & Femi Melinda \\
\hline
\end{tabular}

Kriteria yang digunakan untuk menentukan mahasiswa penerima beasiswa, sebagaimana pada tabel 2 .

Tabel 2. Data Kriteria

\begin{tabular}{cl}
\hline Kriteria & \multicolumn{2}{c}{ Nama Kriteria } \\
\hline K1 & Nilai IPK \\
\hline K2 & $\begin{array}{l}\text { Total Penghasilan } \\
\text { (juta) }\end{array}$ \\
\hline K3 & Pekerjaan Ayah \\
\hline K4 & Pekerjaan Ibu \\
\hline K5 & Jumlah Tanggungan \\
\hline \multicolumn{3}{c}{ Alternatif untuk menentukan } \\
mahasiswa penerima beasiswa bidikmisi,
\end{tabular}

sebagaimana pada tabel 3 . Tabel 3. Data Alternatif

\begin{tabular}{cc}
\hline $\begin{array}{c}\text { Alter- } \\
\text { natif }\end{array}$ & $\begin{array}{c}\text { Nama } \\
\text { Alternatif }\end{array}$ \\
\hline A1 & 1603115225 \\
\hline A2 & 1503114632 \\
\hline A3 & 1503113000 \\
\hline A4 & 1503117345 \\
\hline A5 & 1503114835 \\
\hline A6 & 1403110831 \\
\hline A7 & 1403113611 \\
\hline A8 & 1503121139 \\
\hline A9 & 1503117235 \\
\hline A10 & 1503113119 \\
\hline
\end{tabular}

Bobot kriteria yang diberikan adalah dari nilai 1-100, sebagaimana pada tabel 4.

Tabel 4. Bobot Kriteria

\begin{tabular}{cc}
\hline Kriteria & Bobot $\left(\boldsymbol{w}_{\boldsymbol{j}}\right)$ \\
\hline $\mathrm{K} 1$ & 80 \\
\hline $\mathrm{K} 2$ & 70 \\
\hline $\mathrm{K} 3$ & 50 \\
\hline $\mathrm{K} 4$ & 40 \\
\hline $\mathrm{K} 5$ & 30 \\
\hline
\end{tabular}

Nilai sub kriteria untuk setiap alternatif, adalah sebagaimana pada tabel 5. Sedangkan nilai kriteria untuk masing-masing alternatif sebagaimana pada tabel 6.

Langkah perhitungan metode SMART adalah sebagai berikut :

1) Menghitung normalisasi kriteria menggunakan persamaan (1), yaitu

$$
W_{1}=\frac{80}{80+70+50+40+30}=0,30
$$

Dengan cara yang sama diperoleh normalisasi kriteria, pada tabel 7. 
DOI: https://doi.org/10.33330/jurteksi.v6i3.549

Available online at http://jurnal.stmikroyal.ac.id/index.php/jurteksi

Tabel 7. Normalisasi Bobot Kriteria

\begin{tabular}{ccc}
\hline Kriteria & $\begin{array}{c}\text { Bobot } \\
\text { Kriteria }\end{array}$ & $\begin{array}{c}\text { Normalisasi } \\
\text { Bobot kriteria }\end{array}$ \\
\hline $\mathrm{K} 1$ & 80 & 0,30 \\
\hline $\mathrm{K} 2$ & 70 & 0,26 \\
\hline $\mathrm{K} 3$ & 50 & 0,19 \\
\hline $\mathrm{K} 4$ & 40 & 0,15 \\
\hline $\mathrm{K} 5$ & 30 & 0,11 \\
\hline
\end{tabular}

2) Menentukan nilai utility setiap kriteria.

Sifat untuk masing-masing kriteria adalah sebagaimana pada tabel 8 .

Tabel 8. Sifat-sifat Kriteria

\begin{tabular}{cc}
\hline Kriteria & Sifat Kriteria \\
\hline K1 & lebih besar lebih baik \\
\hline K2 & lebih kecil lebih baik \\
\hline K3 & lebih kecil lebih baik \\
\hline K4 & lebih kecil lebih baik \\
\hline K5 & lebih besar lebih baik
\end{tabular}

Berdasarkan tabel 6 dan tabel 5, A1 dengan nilai-nilai (K1) 3,39 bernilai 2, (K2) 1,5 bernilai 3, (K3) Pedagang bernilai 2, (K4) Pedagang bernilai 2, dan (K5) ialah 2 bernilai 1. Dengan cara yang sama untuk A2, A3, sampai A10 diperoleh nilai-nilai sebagaimana pada tabel 9.

Tabel 9. Nilai Alternatif dan Kriteria

\begin{tabular}{cccccc}
\hline Alter- & \multicolumn{5}{c}{ Kriteria } \\
\cline { 2 - 6 } natif & K1 & K2 & K3 & K4 & K5 \\
\hline A1 & 2 & 3 & 2 & 2 & 1 \\
\hline A2 & 3 & 3 & 2 & 3 & 1 \\
\hline A3 & 2 & 3 & 3 & 3 & 2 \\
\hline A4 & 2 & 3 & 2 & 1 & 2 \\
\hline A5 & 3 & 3 & 3 & 3 & 2 \\
\hline A6 & 3 & 3 & 3 & 3 & 2 \\
\hline A7 & 3 & 4 & 3 & 2 & 2 \\
\hline A8 & 2 & 3 & 2 & 2 & 2 \\
\hline A9 & 2 & 4 & 3 & 2 & 2 \\
\hline A10 & 3 & 4 & 3 & 2 & 1 \\
\hline
\end{tabular}

Berdasarkan Tabel 9, untuk K1 diperoleh

$\mathrm{C}_{\text {max }}=\max (2,3,2,2,3,3,3,2,2,3)=3$

$\mathrm{C}_{\min }=\min (2,3,2,2,3,3,3,2,2,3)=2$

Sehingga dengan tabel 5 nilai utility diperoleh dengan menggunakan persamaan (3), yaitu

$$
u_{1}\left(a_{1}\right)=\frac{(2-2)}{(3-2)}=0,0
$$

Dengan cara yang sama diperoleh

$$
\begin{array}{ll}
u_{1}\left(a_{2}\right)=1,0 & u_{1}\left(a_{7}\right)=1,0 \\
u_{1}\left(a_{3}\right)=1,0 & u_{1}\left(a_{8}\right)=0,0 \\
u_{1}\left(a_{4}\right)=0,0 & u_{1}\left(a_{9}\right)=0,0 \\
u_{1}\left(a_{5}\right)=0,0 & u_{1}\left(a_{10}\right)=1,0 \\
u_{1}\left(a_{6}\right)=1,0 &
\end{array}
$$

Untuk K2, nilai utility diperoleh menggunakan persamaan (2), yaitu

$\mathrm{C}_{\max }=\max (3,3,3,3,3,3,4,3,4,4)=4$

$\mathrm{C}_{\min }=\min (3,3,3,3,3,3,4,3,4,4)=3$

Sehingga diperoleh

$$
u_{2}\left(a_{1}\right)=\frac{(4-3)}{(4-3)}=1,0
$$

Dengan cara yang sama diperoleh

$$
\begin{array}{ll}
u_{2}\left(a_{2}\right)=1,0 & u_{2}\left(a_{7}\right)=0,0 \\
u_{2}\left(a_{3}\right)=1,0 & u_{2}\left(a_{8}\right)=1,0 \\
u_{2}\left(a_{4}\right)=1,0 & u_{2}\left(a_{9}\right)=0,0 \\
u_{2}\left(a_{5}\right)=1,0 & u_{2}\left(a_{10}\right)=0,0
\end{array}
$$

Untuk K3, K4, dan K5 nilai utility diperoleh dengan persamaan (3), sebagaimana pada tabel 10 .

Tabel 10. Hasil Nilai Utility

\begin{tabular}{cccccc}
\hline \multirow{2}{*}{$\begin{array}{c}\text { Alter- } \\
\text { natif }\end{array}$} & \multicolumn{5}{c}{ Kriteria } \\
\cline { 2 - 6 } A1 & K1 & K2 & K3 & K4 & K5 \\
\hline A2 & 1,0 & 1,0 & 1,0 & 0,5 & 0,0 \\
\hline A3 & 0,0 & 1,0 & 0,0 & 0,0 & 1,0 \\
\hline A4 & 0,0 & 1,0 & 1,0 & 1,0 & 1,0 \\
\hline A5 & 1,0 & 1,0 & 0,0 & 0,0 & 1,0 \\
\hline A6 & 1,0 & 1,0 & 0,0 & 0,0 & 1,0 \\
\hline A7 & 1,0 & 0,0 & 0,0 & 0,5 & 1,0 \\
\hline A8 & 0,0 & 1,0 & 1,0 & 0,5 & 1,0 \\
\hline A9 & 0,0 & 0,0 & 0,0 & 0,5 & 1,0 \\
\hline A10 & 1,0 & 0,0 & 0,0 & 0,5 & 0,0 \\
\hline
\end{tabular}


DOI: https://doi.org/10.33330/jurteksi.v6i3.549

Available online at http://jurnal.stmikroyal.ac.id/index.php/jurteksi

3) Menghitung nilai akhir.

Berdasarkan tabel 7 dan tabel 10, dengan menggunakan persamaan (4), diperoleh

$$
\begin{aligned}
& u\left(a_{1}\right)=(0,30 \times 0,0)+(0,26 \times 1,0) \\
& +(0,19 \times 1,0)+(0,15 \times 0,5) \\
& +(0,11 \times 0,0) \\
& u\left(a_{1}\right)=0,53
\end{aligned}
$$

Dengan cara yang sama diperoleh nilai

\begin{tabular}{|c|c|c|c|}
\hline Alter- & & Kriteria & Nilai \\
\hline & K1 & $\begin{array}{llll}\text { K2 } & \text { K3 } & \text { K4 } & \text { K5 } \\
\end{array}$ & \\
\hline A1 & 0,00 & $0,260,190,080,00$ & 0,53 \\
\hline A2 & 0,30 & $0,260,190,000,00$ & 0,75 \\
\hline A3 & 0,00 & $0,260,000,000,11$ & 0,37 \\
\hline A4 & 0,00 & $0,260,190,150,11$ & 0,71 \\
\hline A5 & 0,29 & $0,260,000,000,11$ & 0,66 \\
\hline A6 & 0,30 & $0,260,000,000,11$ & 0,67 \\
\hline A7 & 0,30 & $0,000,000,080,11$ & 0,49 \\
\hline A8 & 0,00 & $0,260,190,080,11$ & 0,64 \\
\hline A9 & 0,0 & 080,11 & 0,19 \\
\hline A10 & 0,30 & $0,000,000,080,00$ & 0,38 \\
\hline
\end{tabular}
akhir untuk masing-masing alternatif. pada tabel 11.

Tabel 11. Nilai Akhir Normalisasi

Berdasarkan tabel 11, bahwa alternatif yang direkomendasikan sebagai penerima beasiswa bidikmisi adalah alternatif A2 dimana A2 adalah mahasiswa dengan NIM 1503114632 atas nama Sesri Jumiatul Erda dengan nilai akhir 0,75 .

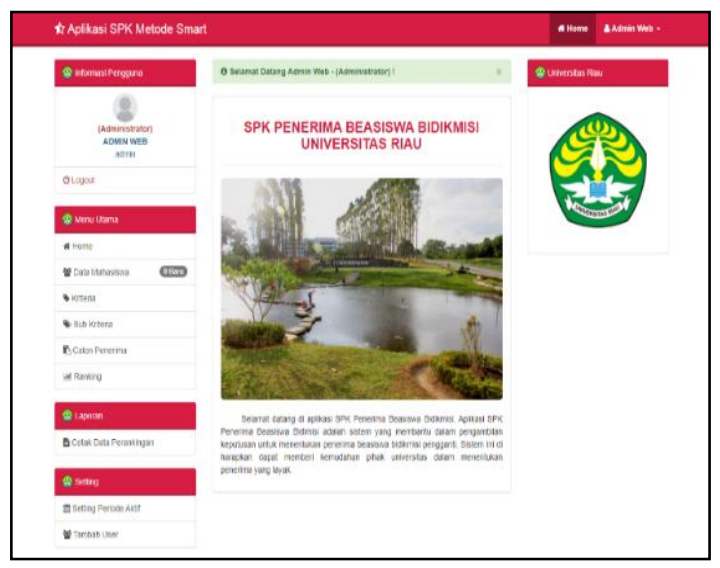

Gambar 3. Halaman Menu Utama
1) Tampilan Halaman Mengelola Data Mahasiswa pada gambar 4 .

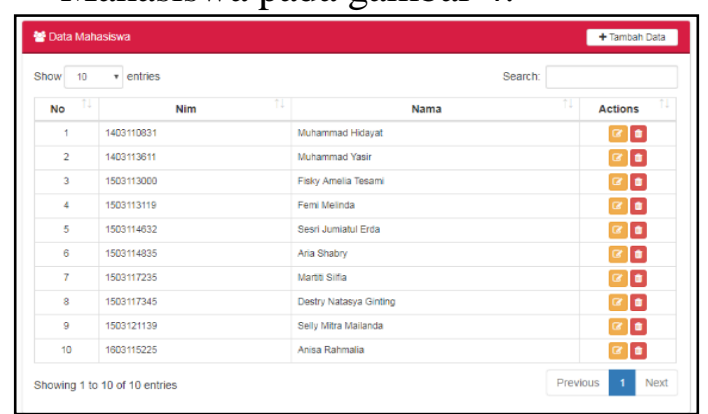

Gambar 4. Halaman Mengelola Data

\begin{tabular}{|c|c|c|c|c|c|}
\hline \multicolumn{5}{|c|}{ Vadh Kiteria } & +Tanion Dala \\
\hline \multicolumn{3}{|c|}{ Show 10 , entries } & \multicolumn{3}{|c|}{ Search } \\
\hline No & Kriteria & Bobot & Bobot Relasiff & Sifit & Actions \\
\hline 1 & Nä Iaza SUHSIKNA & $n$ & 0266 & $\begin{array}{l}\text { Na Lesh Beser } \\
\text { Lesh Dingnian }\end{array}$ & 80 \\
\hline 2 & Tod Pengrasian Oragyta & 70 & 0259 & $\begin{array}{l}\text { Ná Leon Keell } \\
\text { Lebin Dinginan }\end{array}$ & 80 \\
\hline 3 & Peleganan Ajat & 50 & 0.185 & $\begin{array}{l}\text { Nai Lebh Kesil } \\
\text { Lesh Dingizan }\end{array}$ & 80 \\
\hline 4 & Pelegana lou & 49 & 0.14 & $\begin{array}{l}\text { Nal Lebh Keell } \\
\text { Lebin Oingnilan }\end{array}$ & 80 \\
\hline 5 & Jumlan Tangyvgrgan & 30 & 0111 & 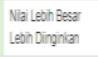 & 80 \\
\hline Showit & 9105 of 5 entives & & & Previous & 1 Nent \\
\hline
\end{tabular}
Mahasiswa

2) Tampilan Halaman Mengelola Kriteria pada gambar 5 .

Gambar 5. Halaman Mengelola Kriteria

3) Tampilan Halaman Mengelola Sub Kriteria, lihat pada gambar 6.

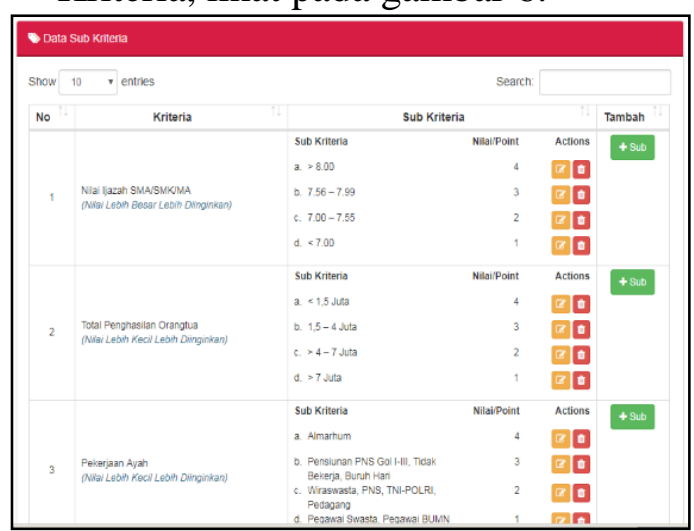

Gambar 6. Halaman Mengelola Sub Kriteria

4) Tampilan Halaman Mengelola Alternatif, dapat dilihat pada gambar 7. 
DOI: https://doi.org/10.33330/jurteksi.v6i3.549

Available online at http://jurnal.stmikroyal.ac.id/index.php/jurteksi

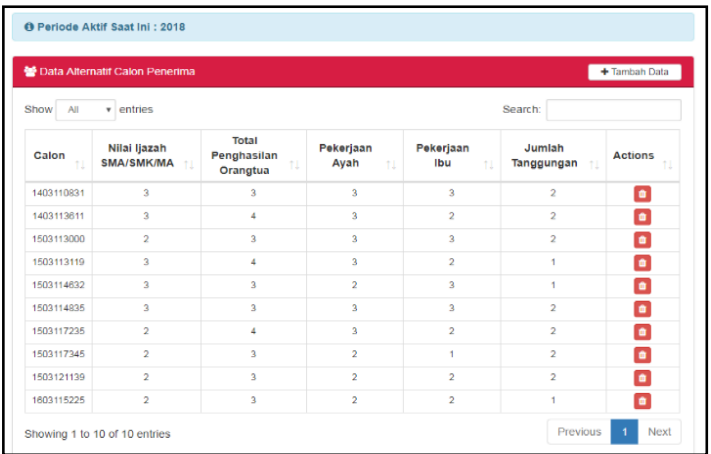

Gambar 7. Halaman Mengelola Alternatif

5) Tampilan Halaman Hasil Akhir, dapat dilihat pada gambar 8 .

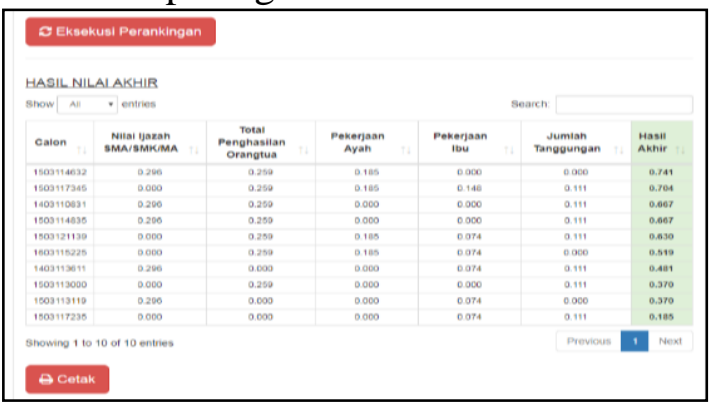

Gambar 8. Halaman Hasil Akhir

\section{SIMPULAN}

Proses perhitungan dengan menggunakan metode SMART berdasarkan kriteria (Nilai IPK, Penghasilan Orang Tua, Pekerjaan Ayah, Pekerjaan Ibu, dan Jumlah Tanggungan) dengan 10 data percobaan diperoleh urutan nilai dari yang tertinggi sampai terendah. Adapun prioritas urutan 3 orang mahasiswa penerima beasiswa adalah A2 (Sesri Jumiatul Erda) A4 (Destry Natasya G.), dan A6 (Muh. Hidayat).

Tabel 5. Nilai Sub Kriteria

\begin{tabular}{|c|c|c|c|}
\hline Kriteria & Sub Kriteria & $\begin{array}{c}\text { Nilai } \\
\text { Kriteria }\end{array}$ & $\begin{array}{c}\text { Bobot } \\
\text { Kriteria }\end{array}$ \\
\hline \multirow{4}{*}{ K1 } & $>3.82$ & 4 & \multirow{4}{*}{80} \\
\hline & $3.56-3.82$ & 3 & \\
\hline & $3.00-3.55$ & 2 & \\
\hline & $<3.00$ & 1 & \\
\hline \multirow{4}{*}{ K2 } & $<1,5$ Juta & 4 & \multirow{4}{*}{70} \\
\hline & $1,5-4$ Juta & 3 & \\
\hline & $>4-7$ Juta & 2 & \\
\hline & $>7$ Juta & 1 & \\
\hline \multirow{4}{*}{ K3 } & Almarhum & 4 & \multirow{4}{*}{50} \\
\hline & $\begin{array}{l}\text { Pensiunan PNS Gol I-III, Tidak Bekerja, } \\
\text { Buruh Harian, Supir, Petani, Honorer }\end{array}$ & 3 & \\
\hline & Wiraswasta, PNS, TNI-POLRI, Pedagang & 2 & \\
\hline & Pegawai Swasta, Pegawai BUMN & 1 & \\
\hline \multirow{4}{*}{ K4 } & Almarhum & 4 & \multirow{4}{*}{40} \\
\hline & Ibu Rumah Tangga & 3 & \\
\hline & Wiraswasta, Petani, Pedagang & 2 & \\
\hline & PNS, Pegawai Swasta & 1 & \\
\hline \multirow{3}{*}{ K5 } & $>6$ & 4 & \multirow{2}{*}{30} \\
\hline & $5-6$ & 3 & \\
\hline & $3-4$ & 2 & \\
\hline
\end{tabular}


DOI: https://doi.org/10.33330/jurteksi.v6i3.549

Available online at http://jurnal.stmikroyal.ac.id/index.php/jurteksi

Tabel 6. Data Kriteria dan Alternatif

\begin{tabular}{cccllc}
\hline \multirow{2}{*}{ Alternatif } & \multicolumn{3}{c}{ Kriteria } & \multicolumn{1}{c}{ K4 } & K5 \\
\cline { 2 - 6 } & K1 & K2 & & Pedagang & 2 \\
\hline A1 & 3,39 & 1,5 & Pedagang & Ibu Rumah Tangga & 2 \\
\hline A2 & 3,61 & 4 & Guru (PNS) & Ibu Rumah Tangga & 3 \\
\hline A3 & 3,46 & 1,8 & Buruh Toko Bangunan & Almarhum & 4 \\
\hline A4 & 3,41 & 3,5 & PNS (Pegawai Negeri Sipil) & Ibu Rumah Tangga & 3 \\
\hline A5 & 3,81 & 1,6 & Tukang (Buruh Bangunan) & Ibu & 3 \\
\hline A6 & 3,60 & 1,5 & Buruh & Ibu Rumah Tangga & 3 \\
\hline A7 & 3,57 & 1,2 & Nyadap Karet & Nyadap Karet & 3 \\
\hline A8 & 3,39 & 2 & Wiraswasta & Wiraswasta & 3 \\
\hline A9 & 3,18 & 1,3 & Petani & Petani & 3 \\
\hline A10 & 3,66 & 1,2 & Petani & Petani & 1 \\
\hline
\end{tabular}

\section{DAFTAR PUSTAKA}

[1] G. Permana, A. Rahmatulloh, and Rianto, "Sistem Pendukung Keputusan Layanan Verifikator Pengadaan dengan Metode Simple Multi Attribute Rating Technique (SMART)," Juita, Vol. 6, No. 2, pp. 99-111, 2018.

[2] Risnawati and N. Manurung, "Sistem Pendukung Keputusan dalam Penentuan Mitra Jasa Pengiriman Barang Terbaik di Kota Kisaran Menggunakan Metode Topsis," Jurteksi, Vol. V, No. 2, pp. 133-138, 2019.

[3] Fitriyani, "Sistem Pendukung Keputusan Pemilihan Mahasiswa Berprestasi di STMIK Atma Luhur Pangkalpinang dengan Menggunakan Metode Analytical Hierarchy Process (AHP)," Jurnal Nasional Teknologi dan Sistem Informasi, Vol. 02, No. 02, pp. 109118, 2016.

[4] A. M. Z. Wahyu, N. Safriadi, and H. S. Pratiwi, "Sistem Pendukung Keputusan Pemilihan Mata Kuliah Pilihan Menggunakan Metode Analytic Hierarchy Process," Jurnal Sistem dan Teknologi Informasi,
Vol. 5, No. 2, pp. 160-163, 2017. http://jurnal.untan.ac.id/index.php/ju stin/article/view/18770/15805.

[5] F. Sholikhah, D. H. Satyareni, and C. S. Anugerah, "Perancangan Sistem Pendukung Keputusan Pemilihan Pelanggan Terbaik Menggunakan Metode Simple Additive Weighting (SAW) pada Bravo Supermarket Jombang," Register, Vol. 2, No. 1, pp. 40-50, 2016.

[6] S. Manurung, "Sistem Pendukung Keputusan Pemilihan Guru Dan Pegawai Terbaik Menggunakan Metode Moora," Simetris, Vol. 9, No. 1, pp. 701-706, 2018.

[7] A. Jumadi, Z. Arifin, and D. M. Khairina, "Sistem Pendukung Keputusan Pemberian Kredit Rumah Sejahtera Pada Nasabah Bank Pembangunan Daerah Kalimantan Timur dengan Metode TOPSIS," Jurnal Sistem Informasi Bisnis, Vol. 4, No. 3, pp. 156-163, 2014.

[8] Afrisawati, "Sistem Pendukung Keputusan Penerimaan Pegawai di STMIK Royal Menggunakan Metode Simple Additive Weighting," Jurteksi, Vol. 4, Vo. 1, pp. $\quad 43-50, \quad 2017$. 
DOI: 10.33330/jurteksi.v4i1.23, https://jurnal.stmikroyal.ac.id/index. php/jurteksi/article/view/23/22

[9] H. Mustafidah and H. N. Hadyan, "Sistem Pendukung Keputusan Penentuan Mahasiswa Berprestasi di Universitas Muhammadiyah Purwokerto Menggunakan Metode Weighted Product (WP) (Decision Support System of Excellent Student Determination in Universitas Muhammadiyah Purwokerto Using Weighted," Juita, vol. 5, no. 1, pp. 51-61, 2017.DOI:10.30595/juita.v5i1.1846, http://jurnalnasional.ump.ac.id/index .php/JUITA/article/view/1846/1539

[10] I. M. A. Santosa, "Implementasi Metode Smart Pada Aplikasi Sistem Pendukung Keputusan Pemilihan Sekolah Paud," Jurnal Sistem dan Informatika, Vol. 12, Vo. 1, pp. 157-167, 2017. https://jsi.stikombali.ac.id/index.php/jsi/article/view /136/80.

[11] T. Magrisa, K. D. K. Wardhani, and M. R. A. Saf, "Implementasi Metode SMART pada Sistem Pendukung Keputusan Pemilihan Kegiatan Ekstrakurikuler untuk Siswa SMA," Informatika Mulawarman Jurnal Ilmiah Ilmu Komputer, Vol. 13, No. 1, pp. 4955 , 2018.

DOI: 10.30872/jim.v13i1.648, http://ejournals.unmul.ac.id/index.php/JI M/article/view/648/pdf

[12] S. R. Cholil, A. P. R. Pinem, and V. Vydia, "Implementasi metode Simple Multi Attribute Rating Technique untuk penentuan prioritas rehabilitasi dan rekonstruksi pascabencana alam," Register, Vol. 4, No. 1, pp. 1-6,
2018.

DOI: 10.26594/register.v4i1.1133, http://journal.unipdu.ac.id:8080/in dex.php/register/article/view/1133/ pdf.

[13] Z. Azhar, "Penentuan Penempatan Karyawan Baru di PDAM Kisaran dengan Metode SMART," Jurteksi, Vol. IV No. 2, pp. 179184 , 2018. DOI: 10.33330/jurteksi.v4i2.46, https://jurnal.stmikroyal.ac.id/inde x.php/jurteksi/article/view/46/43

[14] T. Syahputra, M. Yetri, and S. D. Armaya, "Sistem Pengambilan Keputusan Dalam Menentukan Kualitas Pemasukan Pangan Segar Metode Smart," Jurteksi, Vol. IV, No. 1, pp. 7-12, 2017. DOI: $10.33330 /$ jurteksi.v4i1.19, https://jurnal.stmikroyal.ac.id/inde x.php/jurteksi/article/view/19/18

[15] R. Fauzan, Y. Indrasary, and N. Muthia, "Sistem Pendukung Keputusan Penerimaan Beasiswa Bidik Misi di POLIBAN dengan Metode SAW Berbasis Web," Jurnal Online Informatika, Vol. 2, Vo. 2, pp. 79-83, 2018. DOI: 10.15575/join.v2i2.101, https://join.if.uinsgd.ac.id/index.ph p/join/article/view/v2i23/70.

[16] E. G. Sihombing, E. Arisawati, L. S. Dewi, F. Handayanna, and R. Rinawati, "Penerapan Sistem Pendukung Keputusan Dengan Metode Simple Multi Attribute Rating Technique Pada Pemilihan Toko Roti," InfoTekJar, Vol. 3, No. 2, pp. 159-163, 2019. DOI 10.30743/infotekjar.v3i2.998 https://jurnal.uisu.ac.id/index.php/i nfotekjar/article/view/998/pdf 